\title{
Development of the certificate of added qualification in pediatric urology in the U.S.
}

\author{
Christopher S. Cooper, MD; Anthony A. Caldamone, $M D^{2}$
}

'University of lowa School of Medicine, lowa City, IA, United States; ${ }^{2}$ Brown University, Providence, RI, United States

Cite as: Can Urol Assoc J 2017;11 (1-2):10-4. http://dx.doi.org/10.5489/cuaj.4417

"Pediatric surgery exists as a specialty, not to establish a monopoly, but to establish a standard." Sir Dennis Browne

T he establishment of a certified specialty should not have the intent of exclusivity, but rather to raise the standard of care for that specialty. This was certainly the case for pediatric urology. A major force behind the move for subcertification in pediatric urology was that pediatric surgeons already had subcertification and in order to stay competitive on an institutional basis, there was a need to move pediatric urology forward as well.

The American Board of Urology (ABU), after many years of deliberation, approved subspecialization in pediatric urology in 2007, following approval by the American Board of Medical Specialist (ABMS) a year earlier. The criteria set forth philosophically by the $A B U$ was to establish a standard of training that would not only certify individuals for clinical expertise in pediatric urology, but also for advancing the specialty scientifically and academically. Consequently, a two-year fellowship where 12 months would be devoted to clinical training and 12 months to academic pursuits in a broad range of "approved" options was agreed upon.

It is important to realize, however, that the groundwork started in the 1990s, when the subject of pediatric subspecialization in urology was discussed on a recurring basis at the $A B U$ semi-annual meetings. When voted upon, it was quite lopsided, with the only trustees favouring subspecialization being those pediatric urologist(s) on the ABU. Two important developments took place to energize this movement. First, was the establishment of a pediatric inservice examination (PISE), initially administered in 1997 to assess knowledge base in pediatric urology. This became the precursor of the pediatric subcertification examination (PSCE). Secondly, a pediatric urology advisory committee consisting of representatives from pediatric urology stakeholders (Society for Pediatric Urology [SPU], American
Academy of Pediatric [AAP] Section of Urology, Society for Fetal Urology [SFU], and American Association of Pediatric Urologists [AAPU]) was established to administer to the details of subspecialization, esentially doing the "heavy lifting" for the ABU. The effect was to create direct lines of communication between the entire pediatric urology community and the $\mathrm{ABU}$ by meeting regularly, thus cementing the foundation for subspecialization.

Following the establishment of the pediatric urology certificate of added qualification (CAQ), an increase in the number of fellowship spots occurred. In a relatively short span, the number of pediatric urologists has proliferated and currently in the U.S., there are more than 300 full-time pediatric urologists with 28 open fellowship positions annually. Currently, $46 \%$ of fellows in training are women.

The potential for significantly increased production of pediatric urologists generates concern. Recently, however, there have been more fellowship positions than applicants. It appears that anticipated job availability and other market forces may be leading to a self-regulating decrease in the number of fellowship applicants. Results of a recent workforce survey of 255 U.S. pediatric urologists noted that $52 \%$, $7 \%$, and $41 \%$ reported an increase, decrease, or no change in the referral base, respectively (REF). The respondents indicated that minor case volume, such as circumcisions, increased, decreased, or was unchanged in $50.2 \%, 9.9 \%$, and $39.9 \%$, respectively. Major open case volume was thought to have increased, decreased, or was unchanged by $20.2 \%, 43.3 \%$, and $36.5 \%$, respectively. Two-thirds of pediatric urologists indicated that competition was an issue in their geographic area. ${ }^{1}$

The growth of urology fellowships and a trend in subspecialization raises several questions regarding general urology residency training: How much exposure does a general urology resident need in these areas if much of it will subsequently be referred to fellowship-trained subspecialists? Contributing to this question are the current changes in the U.S. healthcare system that are resulting in a decline in solo 
practitioners, with consolidation into larger groups that may also include "community" subspecialists. If less exposure to complex conditions during residency training is acceptable, given the increase in subspecialists, and in light of the rising costs of medical education and the perceived decline of American urologists in the workforce, another question that arises is, "Should urology residency training be shortened?" One consideration is the fact that many patients prefer to obtain their healthcare locally. With this preference in mind, there is still a demand for urologists who have broad-based training across multiple subspecialty areas and are competent to practice what many consider routine "bread-andbutter" urology.
The growth and development of American pediatric urology is indeed a study in strategic planning and perseverance. The adolescent years of pediatric urology are now upon us, with the inherent growing pains of reassessment of training and responding to market forces.

\section{Reference}

1. Shapiro E, Cooper CS, Greenfield S, on behalf of the American Academy of Pediatrics Section on Urology. The American Academy of Pediatrics workforce survey for the Section on Urology 2015; J Pediatr Urol 2016. [Epub ahead of print]. http://dx.doi.org/10.1016/i.jpurol.2016.09.002

Correspondence: Dr. Christopher S. Cooper, University of lowa School of Medicine, lowa City, IA, United States; christopher-cooper@uiowa.edu

\title{
Pediatric urology experience in Canada: Perspectives from south of the border
}

\author{
Jessica Ming, MD; Jessica Hannick, MD \\ Pediatric Urology, The Hospital for Sick Children, Toronto, ON, Canada
}

Cite as: Can Urol Assoc J 2017;11(1-2):10-4. http://dx.doi.org/10.5489/cuaj.4418

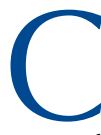

anadian urology residency programs generate approximately 33 urologists annually, ${ }^{1}$ serving 5.6 million children age 14 and younger among a total population of $35000000 .^{2}$ Given the widely dispersed population over a vast geographic area and the fact that the majority of pediatric urologists are concentrated in urban centres, community urologists must manage some pediatric urologic issues locally. Determining which operations and conditions general urologists can deal with presents a challenge for creating requirements for clinical training and for competency.

It has been suggested that Canadian urology residents have insufficient exposure to pediatric urology with suboptimal competency even in low to moderately complex procedures, such as inguinalscrotal surgery and pyeloplasties. Interestingly, $>80 \%$ senior residents and $>75 \%$ urology program directors felt graduating residents were competent in those cases. ${ }^{3}$ Currently, there exist no required number of cases to determine Canadian urology trainee competency. In a recent review of six Canadian programs, on average, residents participated in 149 minor cases and nine major cases. ${ }^{4}$

In contrast, for urology trainees in the U.S., the Accreditation Council for Graduate Medical Education (ACGME) has set a minimum requirement of procedures residents must to be involved in to qualify for board certification. For pediatric urology, these include 30 minor cases (endoscopy, hernia/hydrocele, orchidopexy) and 15 major cases (hypospadias, ureter). ${ }^{5}$ Published national averages for pediatric cases of all graduating U.S. urology residents from 2015-2016 were 121 minor and 63 major cases. ${ }^{6}$ They have also implemented six milestones residents must complete in order to achieve clinical competence, making physician training more accountable to the public.

As current fellows who are U.S. residency-trained and who matched to SickKids for subspecialty training, we compare our residency experiences from that we observed of our local counterparts.

\section{Perspective from a fellow from urban institution that has both a free-standing children's hospital with fellows and a combined adult/pediatric hospital with no fellows}

I spent eight months rotating on the pediatric urology service during my six-year residency. For six of those months during my third and fourth year, I rotated at my home institution, with two fellowship-trained pediatric urologists, no pediatric urology fellows, and one dedicated pediatric inpatient floor. 
I was responsible for participating in staff clinics, covering all consults and the emergency room, and fielding parent calls, but primarily operating as first assist or primary surgeon in all cases.

Two additional months during my fourth year were spent rotating at a major free-standing children's hospital where there were eight fellowship-trained pediatric urologists, one clinical pediatric urology fellow, and at least 3-4 other urology residents. Despite the fellow and increased resident presence compared to Toronto, I continued to do all I had done at my home institution. All of us trainees felt capable of managing basic pediatric problems and performing circumcisions, orchidopexies, and even pyeloplasties by the completion of our training.

After six months in Toronto, it appears that the University of Toronto residents rotate through SickKids for only 2-3 months, as required by the Royal College of Physicians and Surgeons of Canada (RCPSC). Regardless of milestones set by the RCPSC, local residents spend very little time in the operating room (OR) compared to my U.S. contemporaries, reducing the likelihood that they will feel competent and confident to practice basic pediatric urology independently. Should they spend more time in pediatrics with an emphasis on OR rather than clinic (education trumping service) knowing that simulated surgeries and case-based teaching scenarios are not a substitute (yet)? Should they be exposed to the rare and exceptional, not just "bread-and-butter" cases, if we are to spark their interest in pediatrics?

\section{Perspective from a fellow from a rural institution with no free-standing children's hospital or fellows}

Fellowship training in Toronto was appealing because of the high volume of complex cases consolidated into one tertiary institution and also to learn about the Canadian healthcare system. After 1.5 years, it is increasingly evident that residents have minimal exposure to pediatric urology here. Residents rotate on service for only three months total. Coming from a five-year program with one fellowship-trained pediatric urologist, I rotated for six consecutive months on the pediatric service in my fourth year. This intensive time, solely dedicated to pediatrics, allowed for continuity of care, provided a solid foundation of basic concepts, and fostered my interest in the field.

Two months as a junior resident and one month during a senior year, in my opinion, would not have made me feel competent performing surgery on children. In the U.S., residents may only rotate at a maximum of four hospitals and it is required that at least two residents are stationed at any time, which is not the case in Toronto. In the U.S., much of the everyday service is performed by physician extenders (pediatric nurse practitioner and physician assistants), who are overtly absent in this environment, forcing trainees to provide service over education.

As pediatric urology is so subspecialized, it is difficult to determine what general urologists should feel comfortable managing. Even if trainees do not feel confident in operating independently after residency, one should still have adequate exposure to pediatric urology to at least recognize and manage common problems in a community/general urology setting.

Now with specific ACGME milestones set in the U.S., the need for defining competency and determining an adequate case number, it becomes ever more important for residents to have the strongest experiences in every subspecialty. This issue shouldn't be overlooked, as competency-based training matures in Canada.

\section{References}

1. 2014/15 Annual census of post-MD trainees, Canadian post-MD education registry. https://www.cma. ca/Assets/assets-library/document/en/advocacy/Urology-e.pdf. Accessed January 5, 2017.

2. 2011 Census of Canada: Topic-based tabulations. Age groups for the population of Canada, provinces, and territories. https://wwwl2.statcan.gc.ca/census-recensement/2011/dp-pd/tbt-tt/Index-eng.ffm. Accessed January 5, 2017.

3. Mickelson JJ, MackNeily A, Samarasekera D, et al. Competence in pediatric urology upon graduation from residency: Perceptions of residents, program directors, and pediatric urologists. Can Urol Assoc J 2008;2:205-10. https://doi.org/10.5489/cuai.596

4. Gustafson P, MacNeily A. Pediatric procedures in urology residency training: An analysis of the experience of Canadian urology residents. Can Urol Assoc J. 2014;8:317-20. https://doi.org/10.5489/cuaj.2004

5. Accreditation Council for Graduate Medical Education. Case log information for urology programs: Review committee for urology. http://www.acgme.org/Specialties/Documents-and-Resources/pfcatid/26/ Urology. Accessed January 5, 2017.

6. Accreditation Council for Graduate Medical Education. Urology: National resident report (main table). http://www.acgme.org/Data-Collection-Systems/Case-Logs-Statistical-Reports. Accessed January 5, 2017.

Correspondence: Dr. Jessica Ming, Pediatric Urology, The Hospital for Sick Children, Toronto, ON, Canada; jessica.ming@sickkids.ca 


\section{Evolution of pediatric urology}

\author{
Walid A. Farhat, MD
}

Pediatric Urology, The Hospital for Sick Children, Toronto, ON, Canada
Cite as: Can Urol Assoc J 2017;11 (1-2):10-4. http://dx.doi.org/10.5489/cuaj.4419

W ith the advances in diagnostic and therapeutic technologies, urological surgery is rapidly evolving. What once was considered an indication for surgical intervention and part of the surgical logbook, is now treated medically (benign prostatic hyperplasia) or not even at all (vesicoureteral reflux in children). Open surgery is becoming obsolete and different specialties are invading the urology territory with minimal repercussion and major success. For example, interventional radiologists are savvier at approaching the kidney percutaneously and are even treating cancer. Pediatric gynecology has positioned themselves centrally in the care of children with disorders of sexual differentiation. In pediatric urology, the types and complexities of cases have changed dramatically over the last decade, impacting exposure of trainees (fellows and residents) to what used to be common pediatric urological procedures. This change in the surgical exposure will have major impact on the skills gained, competence, and future performance of newly graduating residents.

Almost a decade ago, the Pediatric Urologists of Canada (PUC) acknowledged that Canadian urology residents' exposure to pediatric urology was insufficient. What was most worrisome was the residents' competence in even low- or moderate-complexity cases was deemed inadequate. ${ }^{1}$ It was coincidental that at that same time, pediatric urologists in the U.S. were offered a time-limited Certificate of Added Qualification (CAQ), after successfully completing proper credentialing and case review, as well as passing an examination administered by the American Board of Urology.

In order to improve physician training and lifelong learning, the Royal College of Physicians and Surgeons of Canada (RSPSC) is currently commencing Competence by Design (CBD). CBD will transition specialist medical education from the traditional time-based model to one that is competencybased. This transition is not only timely, but also necessary if we are providing training in general urology that includes care for children with urological pathologies.

The objectives from the RCSPC are determined and categorized by a joint committee composed of members of the Royal College and the Canadian Urological
Association. According to the RCPSC, category A procedures are defined as "all residents must be competent to independently perform..., be able to manage a patient prior to, during, and after ... [and] be able to describe the management of the common complications." Category B procedures are "those that the resident will know how to do, including indications.... the resident may not have actually done one of these procedures independently during the residency training program." Category $\mathrm{C}$ procedures are "those for which the resident will be able to describe the principles of the procedure, indications for referral for the procedure, and particular perioperative problems that might be encountered."

In a recent paper by Gustafson and MacNeily, it was evident that residents were participating in much less common pediatric urology procedures, such as pyeloplasties, ureteral reimplants, or augmentation cystoplasties, compared with other category $A$ procedures, such as circumcision and orchidopexy. With respect to category $B$, the data showed that residents participated in relatively small volume of cases. ${ }^{2}$ This limited surgical exposure would question the resident's competency to perform these procedures independently and with predictably high-quality outcomes upon graduation.

Area of Focused Competence (AFC) diploma programs are post-residency competency-based programs that require additional training. The AFC builds upon a broader discipline in order to enhance scope of practice. AFC diplomas represent areas of medical expertise that respond to significant societal needs. The AFC process is still in its infancy and there are less than a dozen specialties that have been approved. Pediatric urology is seeking such a RCPSC AFC designation. In Canada, the future of pediatric urology appears to be gradually leaning towards becoming a hybrid subspecialty, where in community practices, a general urologist will practice largely adult urology, but be able to perform common pediatric urology procedures. For Canadians, dispersed over a wide geographic area and considering a financially strapped healthcare system, it allows patients and families to remain in their communities with only major procedures continuing to be referred to tertiary/ quaternary healthcare centers. Hence, we see that the AFC 
may provide an opportunity to enhance the surgical skills of the urologists interested in maintaining their practice in pediatric urology and, in the future, such AFC diplomas will expand to other subspecialties within our field.

\section{References}

1. Mickelson JJ, MackNeily A, Samarasekera D, et al. Competence in pediatric urology upon graduation from residency: Perceptions of residents, program directors, and pediatric urologists. Can Urol Assoc J 2008;2:205-10. htrps://doi.org/10.5489/cuai.596

2. Gustafson P, MacNeily A. Pediatric procedures in urology residency training: An analysis of the experience of Canadian urology residents. Can Urol Assoc J 2014;8:317-20. https://doi.org/10.5489/cuai.2004

Correspondence: Dr. Walid A. Farhat, Pediatric Urology, The Hospital for Sick Children, Toronto, ON, Canada; walid.farhat@sickkids.ca

\title{
NEW POSTING — URGENT Urology locum in Barrie, ON
}

We are looking to recruit a urology locum for a busy community practice in Barrie, Ontario. The position is to cover a time period from May to August 2017. Applicants who are available for all or part of this time are welcome to apply.

Barrie is a city in Central Ontario, on the western shore of Lake Simcoe. It offers a historic downtown and a beautiful waterfront area, as well as countless fashion boutiques and a vibrant art scene.

Please send full CV to:

\author{
Dr. Joseph Zadra \\ 1 Quarry Ridge, Suite 202 \\ Barrie, On \\ L4M $7 \mathrm{G} 1$ \\ joezadra@gmail.com
}

